\title{
Therapeutic effect of two fluoride varnishes on white spot lesions: a randomized clinical trial
}

Jainara Maria Soares Ferreira(a) Ana Karla Ramalho Aragão(b) Adriana Dias Batista Rosa ${ }^{(c)}$ Fábio Correia Sampaio(d) Valdenice Aparecida de Menezes ${ }^{(e)}$

(a) MSc in Pedodontics and Preventive Dentistry, Doctorate Student in Pediatric Dentistry; (b) MSc Student in Pediatric Dentistry; (e)PhD - Graduate Program in Dentistry, School of Dentistry, University of Pernambuco, Camaragibe, PE, Brazil.

(c)DDS; (d)PhD, Department of Clinical and Social Dentistry - School of Dentistry, Federal University of Paraíba, João Pessoa, PB, Brazil.

\begin{abstract}
The aim of this randomized clinical trial study was to evaluate the therapeutic effect of two varnish formulations $(\mathrm{G} 1=5 \% \mathrm{NaF}$, $\mathrm{G} 2=6 \% \mathrm{NaF}+6 \% \mathrm{CaF}_{2}$ ) on the remineralization of white spot lesions (WSL). The sample was composed of 15 (7- to 12-year-old) children with 45 active WSL in anterior permanent teeth. The children were randomly divided into two groups providing 22 lesions for G1 and 23 for G2. The children were submitted to weekly varnish applications 4 times. The WSL were evaluated twice: baseline and on week 4. Maximum lesion dimensions (mesiodistal and incisogingival) were measured in millimeters and classified in four grades of size. WSL were also assessed regarding lesion activity by one calibrated examiner. The Pearson chi-square and Fisher's exact tests were used $(P<0.01)$. WSL reductions were observed in both varnish groups (Chi-square $=0.15$, d.f. $=1, P=0.90$ ), and with similar magnitude (in mm): 1.19 and 1.29 for G1 and G2, respectively. Thirtysix WSL (15 in G1 and 21 in G2) were classified as inactive on week 4, reaching an overall value of $80 \%$. No difference was observed between G1 and G2 regarding activity scores (Fisher's exact test, p > 0.01). It was concluded that after 4 applications the two varnish formulations tested produced similar clinical effects, indicating the reduction and the control of carious activity in most WSL. Clinical trial register number: NCT00723515.
\end{abstract}

Descriptors: Dental caries; Tooth remineralization; Fluorides.

\author{
Corresponding author: \\ Jainara Maria Soares Ferreira \\ Av. Mar da Noruega, 66/303, Intermares \\ Cabedelo - PB - Brazil \\ CEP: 58310-000 \\ E-mail: jainara.s@ig.com.br
}

Received for publication on Nov 18, 2008

Accepted for publication on Apr 20, 2009 


\section{Introduction}

The concept of dental caries, initially based on a model proposed by Paul Keyes in 1962 (host, diet and microorganisms), has changed over time. The current concept for dental caries etiology and treatment includes social and behavioral factors regarding individual variables. ${ }^{1}$

White spot lesions (WSL) represent the first clinical observation of demineralization in the enamel and can be regarded as a sign of dental caries. ${ }^{2,3,4}$ A WSL is generally characterized by enamel demineralization of the subsurface, with increasing porosity due to the removal of minerals into the outer surface. ${ }^{5}$ It may be active, with a rough and opaque enamel surface, or inactive, presenting a smooth and shiny enamel surface. ${ }^{4}$

Many reports support that the early diagnosis or detection of WSL and the use of non-invasive therapies such as fluoride are important strategies for controlling the development of a carious lesion. ${ }^{6}$ Several studies indicate that fluoride varnishes can reverse or arrest, as well as prevent, the demineralization process of an incipient carious lesion, when combined with other preventive measures such as diet control and dental biofilm control. ${ }^{7-15}$

Considering the differences in the chemical composition between some domestic and imported fluoride varnishes and also the differences in costs, an assessment of the therapeutic effects of each of these products seems to be of particular interest to Brazilian public health services.

The aim of this study was to evaluate, in a randomized clinical trial, the therapeutic effect of two varnish formulations $(5 \% \mathrm{NaF}$ and $6 \% \mathrm{NaF}+6 \%$ $\mathrm{CaF}_{2}$ ) for controlling the carious development of white spot lesions (WSL).

\section{Materials and Methods}

The study was approved by the Ethics Committee of the Federal University of Paraíba (João Pessoa, PB, Brazil), with final protocol number: 0260/08 and clinical trial register number: NCT00723515.

This was a randomized clinical trial where the randomization of the sample was performed by alternating materials (G1 or G2) weekly in patients who began the research.
A hundred and sixteen children from 7 to 12 years of age with regular hygiene habits (brushing teeth everyday) registered in public schools in the city of João Pessoa, PB, Brazil were examined. The city does not have water fluoridation, and, apart from the fluoride varnish and fluoridated toothpaste, no other fluoride source was available to the subjects. ${ }^{16}$

The inclusion criteria were children with active white spot lesions (roughness and opacity) on the buccal surface of permanent anterior teeth whose parents signed the informed consent form.

Children with dental caries in the form of small cavities or restorations in the target teeth (permanent anterior teeth), developmental enamel alterations (hypoplasia, fluorosis) or periodontal disease, and children using orthodontic devices, under medical treatment or taking any kind of medicine were excluded from this study.

Fifteen of the examined children were selected with 45 active white spot lesions. The randomization was performed by allocation sequence. The children were randomly ordered and sequentially assigned to one intervention group. Apart from the fluoride varnishes tested, fluoridated toothpaste and prophylactic paste, no other fluoride source was available to the subjects. Initial and final S-OHI (Simplified Oral Hygiene Index) scores were recorded. ${ }^{17}$

In all sessions, supervised brushing was conducted prior to each application of topical fluoride. Each patient received a toothbrush (COLGATE Classic Infantil ${ }^{\circledR}$ Colgate-Palmolive, São Paulo, SP, Brazil) and fluoridated toothpaste (COLGATE Máxima Proteção Anticáries ${ }^{\circledR}, 1,500$ ppm of fluoride, Colgate-Palmolive, São Paulo, SP, Brazil) as well as guidance on oral hygiene, so that all of them were given equal means to implement it. Dental prophylaxis was performed with a Robinson bristle brush and prophylactic paste (Herjos- $\mathrm{F}^{\circledR}, 412.3 \mathrm{ppm}$ of fluoride, Rio de Janeiro, RJ, Brazil), in the initial clinical examination and after 4 weeks of treatment, with the aim of providing clean tooth surfaces for the clinical evaluation of the WSL.

Maximum lesion dimension was measured as previously described. ${ }^{18}$ Briefly, the lesion was measured with the aid of a periodontal probe (Trinity ${ }^{\circledR}$, Campo Mourão, PR, Brazil). The values of dimen- 
sion represented the mean of the largest mesiodistal (horizontal) and incisogingival (vertical) diameters in millimeters. The final dimension mean value was also categorized in four levels: A (0.1 to $2 \mathrm{~mm}), \mathrm{B}$ (2.1 to $4 \mathrm{~mm}), \mathrm{C}(4.1$ to $6 \mathrm{~mm})$ and $\mathrm{D}$ (greater than $6 \mathrm{~mm})$.

The white spot lesions were evaluated by dimensional changes and clinical features of texture (roughness or smoothness) and brightness (opacity or shine) to be classified as active (rough and opaque) or inactive (smooth and shiny) as previously described. ${ }^{18}$

The WSL were randomly divided into 2 groups $\left(\mathrm{G} 1=5 \% \mathrm{NaF}\right.$, Duraphat ${ }^{\circledR}$, Colgate Palmolive GmbH, Hamburg, Germany, $\mathrm{n}=22$; and $\mathrm{G} 2=6 \%$ $\mathrm{NaF}+6 \% \mathrm{CaF}_{2}$, Duofluorid XII ${ }^{\circledR}, \mathrm{FGM}$, Joinville, SC, Brazil, $\mathrm{n}=23$ ) and submitted to 4 applications of one of these products once a week according to the manufacturer's recommendations. After 4 weeks, a reevaluation of the white spot lesions was conducted considering dimensional changes and activity (clinical appearance).

Data normality was assessed by the Kolmogorov-Smirnov test using the InStat program (GraphPad Software Inc., San Diego, California, USA). The SPSS (Statistical Package for the Social Sciences, SPSS Inc., Chicago, Illinois, USA) Version 11.0 was used for the statistical calculations. The Pearson's chi-square and Fisher's exact tests were used for comparisons of categorical data. The paired T-test was used to detect significant differences between the initial and final mean values of the WSL. The Student T-test was applied for comparisons between varnish groups when appropriate. An alpha value of 0.01 was previously selected as the indicator for statistical significance.

\section{Results}

The frequency of WSL in G1 and G2 that changed dimension category after fluoride varnish applications is presented in Table 1. Among the WSL that did not show category changes, there were three lesions that showed no real change in dimension measurements in millimeters. Only one lesion increased its dimension in $0.9 \mathrm{~mm}$ and changed category from "A" to "B" in G2. This lesion was classified as hav- ing no reduction of WSL dimension.

Table 2 shows that after 4 varnish applications, both products were effective in reducing WSL dimension values. To illustrate the magnitude of this effect, the mean difference and total percentage of reduction are also presented. Although the mean value of the difference in reduction was higher in G2, the mean difference between groups was only $0.10 \mathrm{~mm}$ and not statistically significant.

Table 3 shows the results for the evaluation of the lesions regarding the classification of activity. There was no significant difference between the varnish groups. Thirty-six WLS out of 45 were classified as inactive after the 4 varnish fluoride applications reaching a value of $80 \%$.

The mean (SD) scores of the S-OHI index were $0.93(0.48)$ and $1.38(0.31)$ for the W1 (initial) and W4 (final) evaluations, respectively. The difference between these means was statistically significant (Paired T test, $\mathrm{p}<0.01$ ).

\section{Discussion}

During the study, the mean oral hygiene scores of the volunteers showed a significant increase and changed from a rather fair good score to a moderate level. This observation may be due to the socioeconomic status of the population studied as observed by previous research in the same area. ${ }^{16}$ In spite of receiving toothbrushes, toothpaste and brushing guidance in each treatment session, volunteers may have a low interest in health issues, and may have access to precarious sanitation and poor healthcare assistance, all of which can affect their compliance as well as their general health. The accumulation of dental biofilm throughout the study as measured by

Table 1 - Distribution of WSL in G1 and G2 that changed dimension category after fluoride varnish applications.

\begin{tabular}{c|c|c|c}
\hline \multirow{2}{*}{ Group } & \multicolumn{2}{|c|}{ Reduction of WSL dimensions } & \multirow{2}{*}{ Total } \\
\cline { 2 - 3 } & $\begin{array}{c}\text { Yes } \\
\mathrm{n}(\%)\end{array}$ & $\begin{array}{c}\text { No } \\
\mathrm{n}(\%)\end{array}$ & (\%) \\
\hline G1 & $13(59.0)$ & $09(41.0)$ & $22(100.0)$ \\
\hline G2 & $14(60.0)$ & $09(40.0)$ & $23(100.0)$ \\
\hline Total & $27(60.0)$ & $18(40.0)$ & $45(100.0)$ \\
\hline
\end{tabular}

(Chi-square $=0.15$, d.f. $=1, P=0.90)$. WSL: White spot lesions. 
Table 2 - Mean (SD) dimension values of WSL according to fluoride varnish group and dimension category. The magnitude of the difference between W4 (week 4, final) and W1 (week 1, initial) is presented as a mean value and percentage.

\begin{tabular}{|c|c|c|c|c|c|c|c|}
\hline \multirow{3}{*}{ Group } & \multirow{3}{*}{$\begin{array}{l}\text { Dimension } \\
\text { category }\end{array}$} & \multicolumn{4}{|c|}{ Week* } & \multicolumn{2}{|c|}{$\begin{array}{l}\text { Difference } \\
\text { (W1-W4) }\end{array}$} \\
\hline & & \multicolumn{2}{|c|}{ W1 (initial) } & \multicolumn{2}{|c|}{ W4 (final) } & \multirow{2}{*}{ Mean } & \multirow{2}{*}{$\%$} \\
\hline & & $\mathrm{n}$ & Mean (SD) & $\mathrm{n}$ & Mean (SD) & & \\
\hline \multirow{5}{*}{ G1 } & $A$ & 4 & $1.90(0.11)$ & 7 & $1.18(0.39)$ & 0.72 & 37.89 \\
\hline & B & 4 & $3.32(0.62)$ & 11 & $3.31(0.51)$ & 0.01 & 0.30 \\
\hline & C & 14 & $4.88(0.43)$ & 4 & $4.57(0.29)$ & 0.31 & 6.35 \\
\hline & $\mathrm{D}$ & 0 & - & 0 & - & - & - \\
\hline & Sub-total & 22 & $4.05(1.27)^{\mathrm{a}, \mathrm{A}}$ & 22 & $2.86(1.33)^{b, A}$ & 1.19 & 29.38 \\
\hline \multirow{5}{*}{ G2 } & A & 6 & $1.38(0.33)$ & 12 & $1.31(0.48)$ & 0.07 & 5.07 \\
\hline & B & 9 & $3.01(0.57)$ & 9 & $2.77(0.45)$ & 0.24 & 7.97 \\
\hline & $\mathrm{C}$ & 6 & 5.45 (1.49) & 1 & $6.00(0)$ & 0.55 & -10.09 \\
\hline & $\mathrm{D}$ & 2 & $7.65(0.50)$ & 1 & $6.80(0)$ & 0.85 & 11.11 \\
\hline & Sub-total & 23 & $3.62(2.13)^{a, A}$ & 23 & $2.33(1.53)^{\mathrm{b}, \mathrm{A}}$ & 1.29 & 35.64 \\
\hline Overall & Total & 45 & $3.83(1.76)^{a}$ & 45 & $2.59(1.45)^{b}$ & 1.24 & 32.38 \\
\hline
\end{tabular}

* Means in the same line followed by distinct superscripts (lower case) indicate statistical significance (Paired T-test, $p<0.01$ ). Means in the same column followed by distinct superscripts (upper case) indicate statistical significance (Student T-test, $p<0.01$ ).

Table 3 - Frequency of WSL classified by activity after 4 varnish applications of both fluoride groups (G1 and G2).

\begin{tabular}{|c|c|c|c|}
\hline \multirow{3}{*}{ Group } & \multicolumn{2}{|c|}{ Activity } & \multirow{2}{*}{ Total } \\
\hline & Active & Inactive & \\
\hline & n (\%) & n (\%) & $\mathrm{N}(\%)$ \\
\hline G1 & 7 (31.8) & $15(68.2)$ & $22(100.0)$ \\
\hline G2 & $2 \quad(8.7)$ & $21(91.3)$ & $23(100.0)$ \\
\hline Total & $9(20.0)$ & $36(80.0)$ & 45 (100.0) \\
\hline
\end{tabular}

(Fisher's exact test, $\mathrm{p}>0.01$ ).

the S-OHI, is an indication of poor compliance of the individuals when using fluoridated toothpaste at home. ${ }^{17,18}$ Therefore, it can be assumed that the remineralization of WSL can be mainly explained by the increase of $\mathrm{CaF}_{2}$ oral reservoirs provided by the fluoride varnish applications and subsequently solubilization of these reservoirs and release of fluoride ions at low $\mathrm{pH} \cdot{ }^{8-14,16-22}$

The better clinical appearance and the good number of lesions that were classified as inactive after four varnish applications supports the hypothesis that highly concentrated fluoridated products have some beneficial effect in spite of the presence of a young dental biofilm. ${ }^{1-3,6}$ Both products tested were effective even though a higher availability of fluoride can be possibly provided by one of the products (G2). The higher number of inactive WSL (Table 3) in G2 cannot be interpreted as real difference. First, no statistical difference was observed between the fluoride varnish groups; second, the evaluation was carried out after 4 fluoride applications only; and third, a higher number of WSL in the $\mathrm{C}$ level was observed in G1 than in G2, in spite of the random distribution (Table 2). In fact, it is known that under a weekly application regimen of fluoridated varnish, 8 weeks can be needed for some active WSL to be classified as inactive. ${ }^{21}$ Unfortunately, the duration of the clinical trials testing the effectiveness of fluoridated varnish products varies considerably, and discrepancies in results have been reported. The controversial results can be mainly ascribed to frequency of varnish application, age span of subjects, level of measurement of the disease and fluoride concentrations and formulations. ${ }^{23-26}$

There is evidence that $\mathrm{NaF}$ varnishes are indeed effective in increasing the fluoride uptake and reducing mineral loss of the enamel under different circumstances. ${ }^{26,27}$ Although the $\mathrm{CaF}_{2}$ in the formula of G2 can possibly prolong the presence of fluoride in 
the mouth due to an increase of more calcium binding sites, its anticarious effect was the same when compared to that of the regular varnish*. Our data show that after 4 applications this beneficial aspect of the formula is not apparent when compared to a simple formula with $\mathrm{NaF}$ alone. On the other hand, a clinical trial with dental biofilm analysis and $\mathrm{F}$ enamel uptake measurements would be worth performing in order to provide more data on this issue.

Certainly, one beneficial aspect of the G2 varnish is the improvement of cost-effectiveness in health programs for caries control since this product is around 10 times less expensive than the G1 and other similar fluoridated varnishes. Being as effective as $\mathrm{NaF}$ varnishes can be an important factor for public health services when planning the prevention or treatment of dental caries, particularly in young children. Nowadays, there is evidence enough that fluoride varnish is effective for arresting early enam-

\section{References}

1. Fejerskov $\mathrm{O}$. Changing paradigms in concepts on dental caries: consequences for oral health care. Caries Res. 2004;8(3):18291.

2. Monteiro JRS, Andrada MAC, Baratieri LN. Remineralização de lesões cariosas incipientes. Rev Gaúcha Odont. 1985;33(3):1859.

3. Baldissera RA, Dias JC, Busato ALS. Remineralização de cárie incipientes. Rev Gaúcha Odont. 1987;35(5):388-91.

4. Zero DT. Dental caries process. Dent Clin North Am. 1999;43(4):635-63.

5. Kidd EAM, Fejerskov O. What constitutes dental caries? Histopathology of carious enamel and dentin related to the action of cariogenic biofilms. J Dent Res. 2004;83(1):C35-C38.

6. Stahl J, Zandona AF. Rationale and protocol for the treatment of non-cavitated smooth surface carious lesions. Gen Dent. 2007;55(2):105-11.

7. Seppä L, Tuuitti H, Luoma H. Three-year report on caries prevention using fluoride varnish application for risk children in a community with fluoridated water. Scand J Dent Res. 1982;90(2):89-94.

8. Seppä L, Pollanen L. Caries preventive effect of two fluoride varnishes and a fluoride mouthrinse. Caries Res. 1987;21(4):375-9. el lesions in primary and permanent dentition..$^{7-9,25}$ In addition, it is a method well accepted by patients. ${ }^{28}$ Nevertheless, the protective effect of these products must be frequently evaluated and monitored preferably under in vivo conditions.

The mean magnitude of caries reduction as measured in millimeters can be regarded as relevant data. If not for the millimeters gained in "sound" enamel, at least the better clinical appearance of the dental enamel could be regarded as a strong argument in favor of increasing compliance of non-cooperative patients in oral health programs.

\section{Conclusion}

It can be concluded that the two varnish formulations tested produced similar clinical effects after 4 applications. This observation indicates a reduction and control of the carious activity in most white spot lesions examined.

9. Seppä L. Studies of fluoride varnishes in Finland. Proc Finn Dent Soc. 1991;87(4):541-7.

10. Queiroz F, Lins BAP, Valença AMG, Soares Filho PJ. Estudo comparativo do efeito dos vernizes fluoretados Duraphat e Fluorniz em lesões incipientes de cárie em esmalte. Rev Fac Odont da Univ de Passo Fundo. 2003;8(2):62-7.

11. Weintraub JA, Ramos-Gomez F, Jue B, Shain S, Hoover CI, Featherstone JD et al. Fluoride varnish efficacy in preventing early childhood caries. J Dent Res. 2006;85(2):172-6.

12. Khattak MF, Conry JP, Ko CC. Comparison of three topical fluorides using computer imaging. J Clin Pediatr Dent. 2005;30(2):139-44.

13. Weintraub JA, Ramos-Gomez F, Jue B, Shain S, Hoover CI, Featherstone JD et al. Fluoride varnish efficacy in preventing early childhood caries. J Dent Res. 2006;85(2):172-6.

14. Borutta A, Reuscher G, Hufnagl S, Möbius S. Caries prevention with fluoride varnishes among preschool children. Gesundheitswesen. 2006;68(11):731-4.

15. Olympio KPK, Cardoso VES, Bijellla MFB, Pessan JP, Delbem ACB, Buzalaf MAR. Urinary fluoride output in children following the use of a dual-fluoride varnish formulation. J Appl Oral Sci. 2009 Jun;17(3):179-83.

\footnotetext{
*Delbem ACB, Oliveira FAL, Brighenti FL, Pessan JP, Buzalaf MAR, Sassaki KT. Fluoride varnishes: anticariogenic action of an experimental coat. J Appl Oral Sci. Forthcoming 2009.
} 
16. Carvalho TS, Kehrle HM, Sampaio FC. Prevalence and severity of dental fluorosis among students from João Pessoa, PB, Brazil. Braz Oral Res. 2007;21(3):198-203.

17. Greene JC, Vermillion JR. The simplified oral hygiene index. J Am Dent Assoc. 1964;68(1):25-31.

18. Ferreira JMS, Silva MF, Oliveira AF, Sampaio FC. Evaluation of different methods for monitoring incipient carious lesions in smooth surfaces under fluoride varnish therapy. Int J Paediatr Dent. 2008;18(4):300-5.

19. Rolla G. On the role of calcium fluoride in the cariostatic mechanism of fluoride. Acta Odontol Scand. 1988;46(6):3415.

20. Ögaard B. Effects of fluoride on caries development and progression in vivo. J Dent Res. 1990;69 spec n':813-9.

21. Rolla G, Oggard B, Cruz AR. Topical application of fluorides on teeth. New concepts of mechanism of interaction. J Clin Periodontol. 1993;20(2):105-8.

22. ten Cate JM. Review on fluoride, with special emphasis on calcium fluoride mechanisms in caries prevention. Eur J Oral Sci. 1997;105(5):461-5.
23. Rodgers J. Fluoride varnish as a public health measure to reduce caries. Evid Based Dent. 2008;9(1):9-10.

24. Guelmann M. Fluoride varnish application: not always effective in public health trials. J Evid Based Dent Pract. 2008;8(2):87-8.

25. Autio-Gold J. Recommendations for fluoride varnish use in caries management. Dent Today. 2008;27(1):64-7;quiz 7,58.

26. Attin T, Lennon AM, Yakin M, Becker K, Buchalla W, Attin $\mathrm{R}$ et al. Deposition of fluoride on enamel surfaces released from varnishes is limited to vicinity of fluoridation site. Clin Oral Investig. 2007;11(1):83-8.

27. Vieira A, Jager DH, Ruben JL, Huysmans MC. Inhibition of erosive wear by fluoride varnish. Caries Res. 2007;4(1)1:617.

28. Xhemnica L, Sulo D, Rroço R, Hysi D. Fluoride varnish application: a new prophylactic method in Albania. Effect on enamel carious lesions in permanent dentition. Eur J Paediatr Dent. 2008;9(2):93-6. 